\title{
FAMIGERADO, SER OU NÃO SER? REFLEXÕES ACERCA DA (RE-) SIGNIFICAÇÃO
}

Pablo Lemos Berned

RESUMO ${ }^{(}$: $\bigcirc$ presente trabalho propõe-se a percorrer os caminhos da significação e da resignificação, através da análise do conto Famigerado, de Guimarães Rosa. Para isso, recorrer-se-á a uma relação entre as concepções de língua e significação de Saussure e de uma perspectiva discursiva

PALAVRAS-CHAVE: (re-) significação, língua, discurso.

\section{INTRODUÇÃO}

Tem-se presente, no mito judaicocristão da Criação do mundo, a figura de Deus que, após evocar o surgimento da luz (em um bom exemplo de enunciado performativo austiniano) e separá-la das trevas, chama-a dia; e às trevas, chama-a noite. $E$ ao longo dos seis dias da Criação, após fazer os elementos e ver que eram bons, nomeava-os. Não bastasse Deus ter feito o Homem à sua imagem e semelhança, segundo a mesma crença, ainda o teria levado a ver todos os animais da terra e dos céus, para que sua principal criatura pudesse nomeá-los, cunhando-lhes seus verdadeiros nomes (Gênesis 1,1-2,20). Este ato de atribuir um nome a algo (ou a alguém, como num batismo) estabeleceria a tentativa de selar a relação entre nomes e coisas, imagem acústica e conceito, significantes e significados.

Sobre a linguagem dada pelo próprio Deus aos homens, era um signo das coisas absolutamente certo e transparente: "Os nomes eram depositados sobre aquilo que designavam, assim como a força está escrita no corpo do leão, a realeza no olhar da águia, como a influência dos planetas está marcada na fronte dos homens: pela forma da similitude" (FOUCAULT, 1995, p.52). Dessa maneira, a relação entre significados e

(C) Trabalho desenvolvido junto ao Grupo de Estudos Lingüísticos - GEL, sob a orientação da prof $\stackrel{\text { a }}{ }$. Dr. Amanda Eloina Scherer. significantes não se daria por uma simples convenção: as coisas tinham sua significação porque se assemelhavam com as palavras. $O$ processo se daria de maneira natural, não arbitrária.

A evocação do mito da Criação vem expor o Homem ao intrínseco desejo de dominar o sentido das palavras. Como apresenta Nunes (2006), desde muito tempo, os sujeitos procuram identificar as palavras, classificá-las, descrevê-las e organizá-las em uma busca de apreensão de um sentido. A proposta de trabalho que aqui se apresenta é situar a posição do ato de significação no âmbito da semântica discursiva.

\section{Em busca da significação}

Quanto ao processo de significação, crê-se ser pertinente reconsiderar a posição de Ferdinand de Saussure ([1916]1987): a língua (langue) é tida como um fato social e como uma estrutura fechada em si mesma, abstrata e sistêmica. Opor-se-ia à fala (parole), constituída por manifestações individuais e momentâneas, que selecionariam parte do sistema da língua para uso em determinadas situações.

Saussure ([1916]1987) desconsidera a visão mecanicista de que a língua é composta por uma lista de termos que correspondam às coisas, de idéias feitas e preexistentes às palavras. Sua proposta é de que o signo lingüístico é uma unidade composta por duas faces indissociáveis (tal como uma moeda): a imagem acústica, que ele chamou de significante; e o conceito, que veio a ser o significado.

A partir desta proposta, deve-se avaliar a teoria de valor de Saussure, em que a relação entre os elementos se dá negativamente (é por ser isso e não outro). Da noção de valor decorreria a significação, "nos limites da palavra considerada como um domínio fechado existente por si próprio" (SAUSSURE, [1916]1987, p.133).

Já uma perspectiva discursiva, para que se possa compreender o processo de 
significação, necessita fundamentalmente da concepção de discurso, de sujeito e de história. Isso porque a significação não existe por si só, atrelada a uma palavra, um objeto ou a alguma coisa. Nem simplesmente por um processo de diferenciação, como é proposto no Curso de Lingüística Geral. Mas ela deve ser compreendida dentro de um processo subjetivo e histórico de significação, em que sejam também consideradas as propriedades diferenciais (tal a concepção saussuriana) e relacionais (de acordo com a Análise de Discurso) da língua (NUNES, 2006).

Tais conceituações serão deslocadas neste trabalho, para o campo de estudos de uma perspectiva discursiva. Aqui haverá a necessidade de se reconsiderar o conceito de língua, ainda visto como um fato social, porém considerado como um sistema aberto. Essa abertura vai superar a dicotomia saussuriana (langue versus parole) e possibilitar que língua e discurso tenham um contato de sobreposição ou de articulação, como afirma Nunes (2006, p.152) sobre essa relação, quando assinala que "a língua é a base do funcionamento do discurso".

Ao se sustentar a relação entre língua e discurso, o que se acrescenta é a admissão de uma prática histórica e ideológica, tanto na concepção de língua quanto na de significação. Isso porque a língua tem a sua história, portanto é suscetível a constantes transformações; seu léxico, conseqüentemente, é afetado pelos processos históricos de significação. Logo, os significados não serão jamais estanques nas palavras: é na ordem do sujeito que se viabilizam as múltiplas significações em potencial.

Pêcheux considera a significação, retomando a dicotomia saussuriana entre língua e fala, pertinente à segunda. Isso porque, ao contrário da tese de Saussure, que vê a significação dentro de um sistema fechado, em contrapartida à imagem auditiva (significante), segundo Mussalim (2004), para Pêcheux

a significação não é sistematicamente apreendida por ser de ordem da fala e, portanto, do sujeito, e não da ordem da língua, pelo fato de sofrer alterações de acordo com as posições ocupadas pelos sujeitos que enunciam (MUSSALIM, 2004, p.105)

Assim sendo, a perspectiva discursiva propõe o deslocamento da dicotomia língua versus fala para se pensar em língua e discurso. Admite-se a língua como um sistema aberto servindo de base para o funcionamento do discurso, cuja noção acolheria o histórico, o social, assim como a ideologia (ORLANDI, 1996). Dessa forma, reconhecer a partir da relação entre língua e discurso que a língua tem a sua história, é admitir que ela esteja em constante transformação e é suscetível a equívocos.

Nessa trajetória, em determinado momento, fez-se necessária uma resignificação das noções de histórico e social (idem), partindo-se da própria teoria do discurso. Desloca-se o sentido de social, de traços sociológicos empíricos, para as formações ideológicas, que corresponderiam a mecanismos de projeção responsáveis pela relação entre situação e posição dos sujeitos, tal como funcionam num discurso. Por sua vez, a história não estaria atrelada a uma sucessão cronológica de acontecimentos, mas às tramas de sentido. A história estaria ligada à memória, constituída por redes de filiações responsáveis pela língua poder significar.

Repudia-se então uma relação objetiva entre pensamento, linguagem e mundo, ao se conceber a relação entre palavras e coisas, numa perspectiva lingüístico-histórica (ORLANDI, 1996). Isso acontece por não serem estanques as significações, e sim suscetíveis às instabilidades, aos movimentos de fronteira e aos deslocamentos, não apenas dos campos lexicais em decorrência do contato do léxico com a história - como aponta Nunes (2006) -, mas oriundos da própria relação existente entre língua e história.

Então a questão da significação (e da re-significação) desemboca por fim em uma relação com a interpretação, pois os sentidos não estariam nas palavras, mas na língua que constitui os sujeitos. Portanto,

o fato lexical é um fato social e, assim sendo, está sujeito às forças sociais, que permeiam as relações entre os sujeitos. $\mathrm{Na}$ articulação com o discurso, a descrição lingüística atenta para esse fato, levando em consideração que as mesmas palavras podem ter sentidos diferentes, conforme as posições sustentadas pelos sujeitos. (NUNES, 2006, p. 152).

Diante desta constatação, torna-se relevante que se considere o caráter opaco (relativo à incompletude) da linguagem: a impossibilidade de apreensão de todos os 
sentidos. A ilusão de totalidade, de transparência, decorreria da interpretação que, por sua vez, estaria subordinada às condições de produção específicas (regidas por uma formação ideológica). "Apagam-se suas condições de produção, desaparece o modo pelo qual a exterioridade o constitui" (ORLANDI, 1996, p.65).

A partir dessas condições específicas, que aparecem para o sujeito como universais e eternas, deriva a ilusão da existência de um sentido único e verdadeiro que ignora a historicidade da língua e, conseqüentemente, o equívoco, a ambigüidade, a opacidade. Ou seja, o reconhecimento de que a língua é suscetível a falhas. Por conseguinte, apesar da ilusão de que os sentidos, ou melhor, de que os significados estão nas palavras, eles podem ser, haverão de ser outros.

\section{Em busca da re-significação}

Ao tomar como corpus de análise o diálogo presente no conto Famigerado, propõe-se a acompanhar o percurso de significação e de re-significação inseridas na perspectiva discursiva. Famigerado é um dos vários contos que compõem Primeiras Estórias (1962), de João Guimarães Rosa. Neste conto, um médico do interior do sertão recebe a visita de um famoso ex-jagunço, desejoso por saber o significado da palavra famigerado, que teria sido atribuída a si por um "moço do Governo".

Para fins analíticos, estabeleceu-se quatro momentos significativos do conto relativos à busca da conceituação do termo em questão, mote da narrativa. O primeiro referese justamente à primeira referência de Damázio dos Siqueiras - o ex-jagunço - à pergunta que o motivara $a$ ir à busca do médico:

— "Vosmecê agora me faça a boa obra de querer me ensinar o que é mesmo que é: fasmisgerado... faz-me-gerado... falmisgeraldo... familhas-gerado...?" [...]

— Famigerado?

- "Sim senhor..." - e, alto, repetiu, vezes, o termo, enfim nos vermelhões da raiva, sua voz fora de foco. (ROSA, [1962] 2001, p.59-60).

Este primeiro momento se estabelece no nível do significante: as tentativas feitas através da fala de Damázio ao termo de significado incógnito atestam as falhas (equívocos) no âmbito da ordem da língua. Segundo Orlandi (1996, p.48), "ao contrário da completude do sistema (abstrato), a ordem significante é capaz de equívoco, de deslize, de falha, sem perder seu caráter de unidade, de totalidade" Verifica-se, sobre a passagem de organização para a ordem da língua, ainda citando Orlandi, que:

\begin{abstract}
o que interessa ao analista de discurso não é a organização do texto, (forma empírica ou abstrata) mas a ordem do discurso (forma material) em que o sujeito se define pela sua relação com um sistema significante investido de sentidos, sua corporeidade, sua espessura material, sua historicidade (ORLANDI, 1996, p.49).
\end{abstract}

Embora Damázio não tenha tido êxito no que concerne à pronúncia de famigerado, o significante é apreendido pelo interlocutor. Isso porque a palavra é portadora de um sistema significante investido de sentidos, de corporeidade, de espessura material, de historicidade; e são estes elementos que permitem tanto ao médico-narrador "adivinhar" o sentido, quanto ao ex-jagunço poder constituí-la.

— Famigerado é inóxio, é "célebre",
"notório", "notável"...
— "Vosmecê mal não veja em minha
grossaria, no não entender. Mais me
diga: é desaforado? É caçoável? É de
arrenegar? Farsância? Nome de
ofensa?" (ROSA, [1962] 2001, p.60).

Neste segundo momento, ante a primeira tentativa de definição de famigerado pelo médico-narrador, poder-se-ia verificar possíveis significações do termo em relação com a história. Pois essa palavra está inserida em um acontecimento lingüístico - em um discurso - situado na história. É o que possibilita à personagem estabelecer uma relação hipotética de múltiplos significados, embora apontem para significados (ainda hipotéticos) de cunho negativo. As hipóteses levantadas por Damázio atestam a falta de uma certeza: afinal, todo sujeito busca sua completude. Enfim, a personagem recorre a um outro, em busca de uma "autoridade" capaz de atestar-Ihe um domínio de língua.

\footnotetext{
- Vilta nenhuma, nenhum doesto. São expressões neutras, de outros usos...
} 
- "Pois... e o que é que é, em fala de pobre, linguagem de em dia-desemana?"

- Famigerado? Bem. É: "importante", que merece louvor, respeito... (ibidem).

Tem-se, neste terceiro momento, inicialmente, uma quebra na expectativa de significação para Damázio. Porém, a utilização, pelo médico-narrador, de vocábulos desconhecidos ao seu interlocutor produz efeito análogo ao do termo famigerado: não há sentido, pois não há uma relação lógica entre o significante e seu significado para 0 interlocutor.

Desta inoperação discursiva (considerando que a língua está suscetível a essas falhas) há uma nova busca de significação, a partir de formações discursivas. Damázio assume uma posição-sujeito determinada ("em fala de pobre, linguagem de em dia-de-semana") para que seu interlocutor possa re-significar seu discurso, constituindo um sentido mediado pela interpretação de cada um. Assim, coube ao médico-narrador deslizar em formações discursivas até fazer-se entendido. De acordo com Orlandi (1988, p.21), "as palavras recebem, pois, seu sentido da formação discursiva na qual são produzidas". É como se o narrador transitasse de uma formação discursiva de homem letrado para a formação discursiva de jagunço pobre de pouca instrução. "Uma palavra recebe sentido na relação com as outras da mesma formação discursiva e o sujeito falante aí se reconhece" (ibidem). É isso que permite a construção de um sentido de famigerado para Damázio:

- "Vosmecê agarante, pra paz das mães, mão na escritura?"

Se certo! Era para se empenhar a barba. Do que o diabo, então eu sincero disse:

- Olhe: eu, como o sr. me vê, com vantagens, hum, o que eu queria uma hora destas era ser famigerado - bem famigerado, o mais que pudesse!...

_ "Ah, bem!... - soltou, exultante" (ROSA, [1962] 2001, p.60).

Houve o desfecho da dúvida de Damázio dos Siqueiras quanto ao significado de famigerado. Porém, pode-se verificar que, para uma personagem, o sentido da palavra em questão constrói-se diferentemente do sentido da outra. "Há uma determinação histórica na constituição dos sentidos e dos sujeitos que têm forma material concreta distinta nas diferentes formas sociais" (ORLANDI, 2002, p.69). Considera-se que, se os sentidos são diferentes, é porque cada personagem é dotada de uma determinada história. "Os sentidos e os sujeitos poderiam ser sujeitos ou sentidos quaisquer, mas não são" (ibidem). Para o médico, a significação de famigerado aponta para um pólo negativo "alguém podia ter feito intriga, invencionice de atribuir-me à palavra de ofensa àquele homem" - , que tem o significado do termo transposto para o pólo oposto. Enquanto isso, para Damázio, que pré-concebeu um significado negativo, é invertido o sentido de famigerado para um pólo positivo.

No entanto há a estranheza, o inusitado proposto pelo conto. O significado de famigerado por fim apresentado pelo narrador não coincide com o seu próprio, tampouco com o do leitor. Observa-se, porém, quanto ao conceito institucionalizado pelo Novo Dicionário Aurélio (1986):

famigerado. [Do lat. famigeratu.] Adj. Que tem fama; muito notável, célebre, famoso, famígero: "Não têm os biógrafos do $f$ a $m$ i g e r a d o romancista achado documentos nem tradições com que esclarecer sobejamente os primeiros anos de Cervantes." (Latino Coelho, Cervantes, pp. 51-52); "Naquela casa de Vila Cova... floresceram... padres de muito saber, uns f a m i g e r a d o s na oratória, outros grandes casuístas" (Camilo Castelo Branco, O Bem e o Mal, p.39); "Tinha visto aquele encaminhar-se à engenhoca, o que o fizera acreditar que entre os malfeitores... se achava 0 f a m i g e r a d o bandido" (Franklin Távora, O Cabeleira, p. 202). [Como se vê nos dois primeiros exemplos, a palavra não se aplica só a malfeitores, embora no uso comum se observe tendência para isso.] 2. Pop. Faminto, esfomeado.

O sentido "negativo" que por ora atribuise à palavra não encontra referência na definição dada pelo dicionário, salvo em uma explicação ao final, entre chaves, e que vai de encontro com a quebra de expectativa do leitor. Enquanto no Dicionário Houaiss (2001):

famigerado adj. (a1727 cf. RB) 1 que tem muita fama; célebre, notável, famígero 2 pej. tristemente afamado $<f$. assaltante $>$ - ETIM lat. famigerātus, a, um 'que divulga notícias, famoso, afamado'; ver fa- 
SIN/VAR ver sinonímia de insigne $\odot$ ANT ver sinonímia de canalha, desconhecido, e mal-afamado.

Há nesta definição uma maior atenção ao sentido negativo do termo, tal qual o sentido explorado pelo conto. Afirma Orlandi: "para que uma palavra faça sentido é preciso que ela já tenha sentido" (1996, p.71). E esse sentido atribuído ao termo (através da narrativa e aceito pelos leitores) seria oriundo do interdiscurso - o que em uma análise discursiva é definido como domínio da memória discursiva, "que sustenta o dizer na estratificação de formulações já feitas, mas 'esquecidas', e que vão construindo uma história dos sentidos" (idem).

Dessa forma, verifica-se que as significações institucionalizadas pelo dicionário acabam por "atestar" o sentido proposto à Damázio pelo médico. No entanto, a memória discursiva (FERREIRA, 2001) que recupera na história da língua as significações que constituem o seu imaginário e o seu simbólico, permite que sujeitos re-signifiquem as palavras, a partir das diferentes formações discursivas.

\section{CONCLUSÃO}

Se, com Saussure ([1916]1987, p. 80), "o signo lingüístico é, pois, uma entidade psíquica de duas faces [...]: esses dois elementos [significado e significante] estão intimamente unidos e um reclama o outro", a perspectiva discursiva apontará uma outra relação. O processo de significação, tal como foi percorrido, não se apresenta como uma ação estanque e perene.

A língua não será considerada um sistema fechado, mas suscetível a equívocos: logo, os significados renovam-se a cada apropriação de um termo por determinados sujeitos. Assim, a formação de sentidos é estabelecida pelo sujeito, decorrente da sua própria história, a história da língua e a história da palavra. Isso sugere que o significado é continuamente re-significado pelos sujeitos, sejam falantes, escreventes, ouvintes ou leitores de cada língua.

\section{REFERÊNCIAS BIBLIOGRÁFICAS}

DICIONÁRIO Houaiss da língua portuguesa.

Rio de Janeiro: Objetiva, 2001. p.1304

FERREIRA, Maria Cristina Leandro. Glossário de Termos do Discurso. Porto Alegre: UFRGS, Instituto de Letras, 2001.

FOUCAULT, Michel [1966]. As palavras e as coisas: uma arqueologia das ciências humanas. São Paulo: Martins Fontes, 1995.

MUSSALIM, Fernanda. Análise do Discurso. In: MUSSALIM; BENTES (orgs.). Introdução à lingüística: domínios e fronteiras (v.2). 4 ed. São Paulo: Cortez, 2004.

NOVO DICIONÁRIO Aurélio de língua portuguesa. $2^{\underline{a}}$ ed. Rio de Janeiro: Nova Fronteira, 1986. p.755

NUNES, José Horta. Lexicologia e lexicografia. In: GUIMARÃES, E.; ZOPPI-FONTANA, M. (orgs.) A palavra e a frase. Campinas, SP: Pontes, 2006.

ORLANDI, Eni Pulccinelli; GUIMARÃES, Eduardo. Unidade e dispersão: uma questão do texto e do sujeito. In: ORLANDI, Eni Pulccinelli [et al.] Sujeito e texto. São Paulo: EDUC, 1988.

ORLANDI, Eni Pulccinelli. Interpretação; autoria, leitura e efeitos do trabalho simbólico. Petrópolis, RJ: Vozes, 1996.

Do Sujeito na História e no Simbólico. In: ORLANDI, Eni P. Língua e conhecimento lingüístico: para uma história das idéias no Brasil. São Paulo: Cortez, 2002.

ROSA, Guimarães [1962]. Primeiras Estórias. 15 ed. Rio de Janeiro: Nova Fronteira, 2001.

SAUSSURE, Ferdinand [1916]. Curso de lingüística geral. $13^{\underline{a}}$ ed. São Paulo: Cultrix, 1987. 